\title{
Pensar es un acto, sentir es un hecho': rehacer prácticas pedagógicas afectivas en el aula universitaria
}

Para Aldo, futuro mentor

\section{Resumen}

$\mathrm{E}$ $\mathrm{n}$ este texto se presentan algunas estrategias didácticas desarrolladas para la enseñanza de la composición de textos en español en el aula universitaria, las cuales parten del reconocimiento de que los sujetos presentes son cuerpos que importan. Para ello, se plantea una metodología sensorial que permite, mediante la narración de imágenes, dar cuenta de las experiencias de un estudiantado que posee razón, afectos y emociones, con lo cual se conforma una geografía sui generis que permite construir ciudadanía desde el salón de clases.

Palabras clave: estrategia didáctica, reconocimiento, metodología sensorial, enseñanza del español, instituciones de educación superior.

En el salón de clases suceden más acontecimientos de los que nos damos cuenta, y la mayoría de las veces influyen en la conformación de las dinámicas escolares y en los procesos de enseñanza y aprendizaje que se realizan, ya que el aula está habitada, aunque parecemos olvidarlo, por sujetos con cuerpo que además de pensar, sienten, hablan e importan. Lo anterior es reconocible mediante la realización de estrategias pedagógicas afectivas que admiten, de manera efectiva, la dignidad del estudiantado y el profesorado. ${ }^{1}$

Una diferencia entre la "buena vida" y la "vida buena" (Ferry, 2009) es que la segunda supone hacerse preguntas respecto a la propia existencia en relación con los demás; en cambio, la primera demanda poseer aquella cultura material que satisface de manera inmediata y conduce al tedio que reclama nuevos satisfactores. En este sentido,

1 Titulo inspirado en la obra "La hora de la estrella" de Clarice Lispector, 2007. pensar es un acto, como refiere Clarice Lispector (2007), que conlleva a percibir de manera distinta lo que nos rodea; en consecuencia, se torna diferente el registro, la interpretación y la significación de lo sentido y reflexionado. En este caso, el orden de los factores (lo cognitivo y lo sensorial) no altera el resultado: la vivencia estético sensual y cognitiva experienciada ${ }^{2}$ por el sujeto.

La experiencia, entendida como aquello que constituye a los sujetos como tales (Scott, 2001), suele ser un elemento clave en la planeación, el desarrollo y la recapitulación de una sesión de clases, así como en la búsqueda y elaboración de materiales didácticos, actividades y las diversas evaluaciones de los desempeños realizados por el estudiantado y el profesorado en su conjunto. No obstante, centrados muchas veces en la obsesión por evaluar y, en

2 Según Denise Najmanovich, experienciar es "dar cuenta de las experiencias no deliberadas ni planeadas" (2016: 264). 


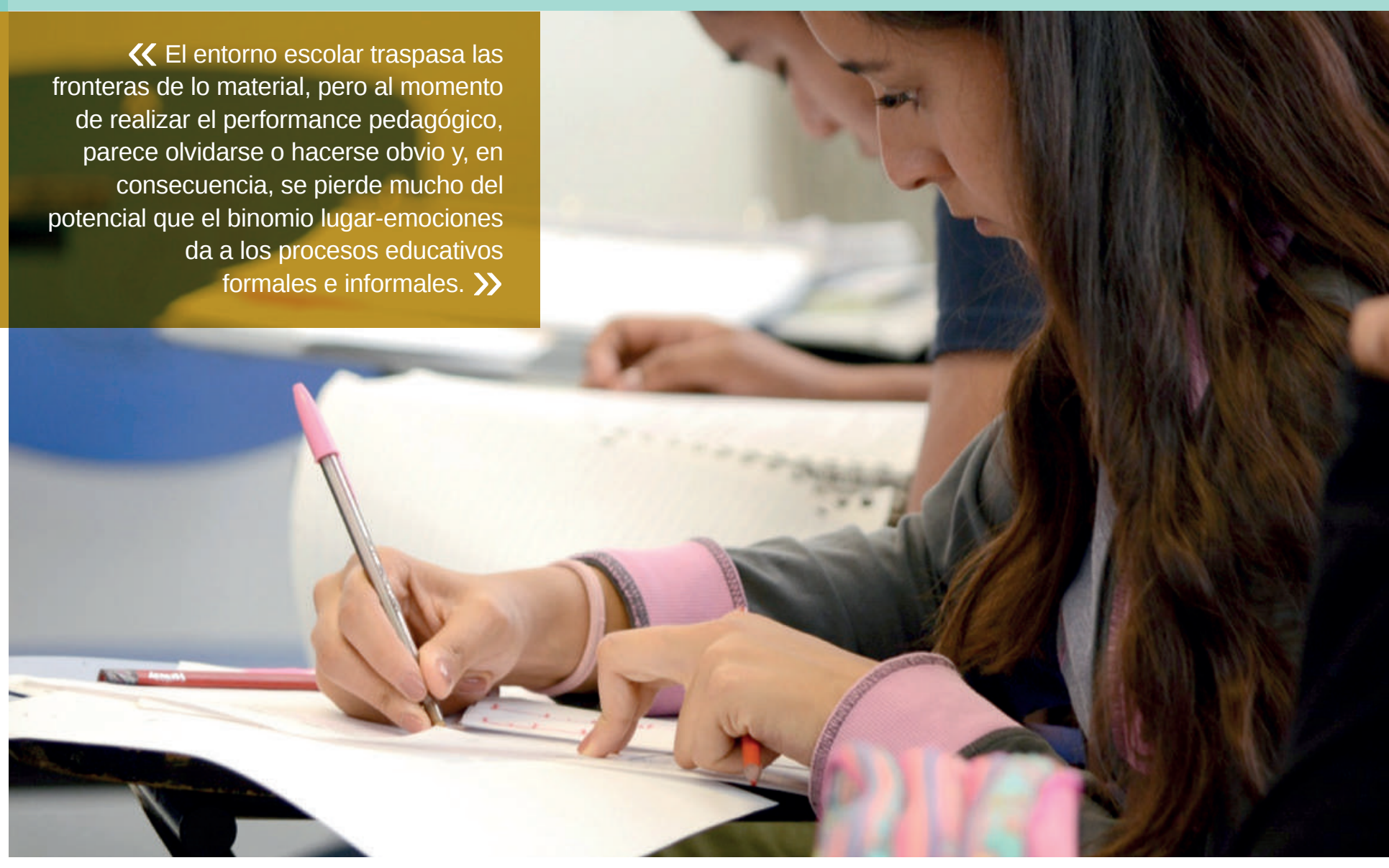

consecuencia, dar puntual cuenta de lo planeado, se deja de lado (y a veces ni siquiera se considera) el importante lugar que tienen las emociones de los estudiantes y los docentes presentes en el aula, un espacio-lugar ${ }^{3}$ significativo, y que su fluidez las hace constitutivas de las relaciones que se establecen entre unos y otros, con lo cual se conforma "algo más" que el clima escolar (Claro, 2013; Herrera y Rico, 2014), y constituyen un andamiaje valioso para la enseñanza y el aprendizaje. El entorno escolar traspasa las fronteras de lo material, pero al momento de realizar el performance pedagógico, ello parece olvidarse o hacerse obvio y, en consecuencia, se pierde mucho del potencial que el binomio lugar-emociones ofrece a los procesos educativos formales e informales.

Mi desempeño académico de los últimos años en instituciones de educación superior (IES),

3 Al respecto, apunta Helena López: Por lugar me refiero a las situaciones materiales concretas -la realidad geográfica de nuestras relaciones sociales- que interactúan en formas espaciales, entendidas éstas como las significaciones discursivas y afectivas: "las estructuras de sentimiento" (López, 2012: 55). la revisión crítica de mi práctica docente, la formación académica actualizada y la reflexión desde enfoques que recuperan el olvidado lugar de lo afectivo en el salón de clases, me han concedido llevar a cabo un trabajo dialógico que considera, además de lo racional (lo que sé y hago desde mis conocimientos teóricos y procedimentales), incluir también lo sensorial que me permite plantearme ¿qué supone reconocer que sentimos y qué sentimos? Toda vez que nuestra percepción está mediada y valorada dentro de una escala sensorial que es una escala social, como apunta Howes (2014: 19): "en cada cultura, los órdenes sensoriales están entrelazados con los ordenamientos sociales". Las implicaciones de identificar que percibimos y qué percibimos y cómo registramos tales percepciones de manera situada (Sabido, 2017) plantea retos y revela sorpresas en el aula.

Algunos autores como Boler (1999); Hargreaves (2001); Ahmed (2006); Youdell y Armstrong (2011); Zembylas, Bozalek y Shefer (2014) han destacado la importancia de las emociones en relación con el aprendizaje, y planteado propuestas para lle- 
var a cabo metodologías que consideren los afectos y las emociones en las dinámicas del salón de clases. Esta propuesta sensorial la puse en diálogo con otra perspectiva: la redacción de textos en español. En este tenor, preparar un curso específico incluye, además de la bibliografía necesaria para dar cuenta documentada del mismo, favorecer la emergencia de un conjunto de escenas pedagógicas que consideren el cuerpo de quienes están presentes en el salón de clases (estudiantado y profesorado): una materialidad en continuo movimiento que percibe, siente, reacciona, piensa, duda y es crítica; fin último de una experiencia educativa y del trabajo académico.

Una estrategia didáctica supone la necesidad de considerar una planeación que va más allá de la misma, una suerte de plan $\mathrm{B}$ e incluso $\mathrm{C}$ que abarca diferentes materiales, así como distintas habilidades que apelen al sentir, pensar, accionar y resistir del estudiantado; me refiero a tener presente en la elaboración de materiales y en los recursos didácticos diseñados los silencios, la apatía, los ruidos, los deseos, las variables que conforman a los sujetos como tales, el horario, el clima, la cantidad de estudiantes, el espacio-lugar y, por supuesto, las expectativas, los límites y las resistencias de quien imparte la clase.

Dar lugar al cuerpo y nombrarlo, además de dotarlo de reconocimiento (Honneth, 1992), demanda considerarlo presente durante todo el proceso del desempeño académico, incluido en el momento obsesivo de la evaluación per se, puesto que consta la imposibilidad de que un estudiante rinda igual en todas las sesiones o durante el transcurso de la misma o con el mismo porcentaje (si acaso pudiese ser medible) que los demás: aspirar a lo anterior, invisibiliza el proceso formativo del estudiantado y niega el carácter humano y humanístico del quehacer académico, en tanto que apuesta por el juego neoliberal obsesionado con la producción y las ganancias; si el cuerpo importa, la evaluación deja de ser central.

El desempeño pedagógico en el salón de clases desborda los registros de una planeación, los objetivos de un programa y los límites de un plan de estudios; todo esto, si bien sienta las bases para un trabajo organizado y objetivo, es ante todo un performance y no es posible ensayarlo ni adelantar sus efectos y consecuencias. Me refiero a una práctica pedagógica ética, responsable, no a la improvisación y al desdén por la institución escolar, expresados en acciones disfrazadas de espontaneidad didáctica o novedosos desempeños académicos.

Un ejemplo de la realización (especifico "realización", porque no soy titular de la experiencia educativa impartida, como tal, recibo un programa elaborado con los temas y formas de evaluación ya establecidos) de un curso que considera lo afectivo y lo cognitivo es el siguiente: durante el periodo agosto 2017-enero 2018 impartí la clase de "Composición de textos en español" en la Facultad de Idiomas, a un total de veintidós estudiantes de la Licenciatura en Lengua Inglesa de la Universidad Veracruzana, cuyas edades comprenden entre los 19 y 22 años, la mayoría venidos de diferentes partes del estado de Veracruz y sureste del país, además de los originarios de la ciudad de Xalapa. Casi todos con historiales académicos no tan exitosos, y que comparten la experiencia de un recorrido escolar tortuoso desde que ingresaron al sistema educativo formal.

En este sentido, el reto fue acercar a la composición de textos académicos específicos a estudiantes que prefieren desempeñarse en inglés antes que en español, que han padecido la enseñanza de la lengua materna a través de castigos y pocos premios, que no consideran útil el aprendizaje de ciertas estrategias y habilidades de escritura, que manifiestan rechazo hacia la práctica lectora y a la redacción en general, y que en el aula no han visto expresados sus deseos y necesidades escolares ni recibido algún tipo de acompañamiento académico.

Al programa (objetivos) y al plan de estudios (contenidos) de la asignatura sumé el abordaje de los temas mediante una metodología sensorial que colocó en el centro de la práctica docente las maneras de percibir del estudiantado y sus experiencias. De este modo, el pase de lista perdió su naturaleza punitiva para ser meramente una cuestión administrativa, y se modificó la obligatoriedad de redactar textos de determinado número de palabras según la voluntad del docente, para darle al alumnado la libertad, y con esto la responsabilidad, de elegir los temas a partir de los que producirá sus propios textos y también la extensión de los mismos.

Para empezar, se les invitó a redactar textos informales a través de la composición de fragmentos y frases breves, propias de su realidad como jóvenes universitarios: estados de Facebook, así como tuits y memes. El siguiente paso fue recurrir a textos más extensos como canciones, poemas y cuentos de 
su elección para identificar las estructuras formales de su constitución. Finalmente, llegamos a la composición de los textos académicos planteados en los objetivos del programa de la experiencia educativa.

La consideración de una metodología sensorial (narrar imágenes y contar desde la subjetividad de cada estudiante) generó inicialmente un desconcierto y un bloqueo después, puesto que los estudiantes no suelen estar habituados a que en el espacio académico ingresen textos de su cotidianidad, ni suele ser común que puedan elegir sobre los temas que quieren abordar en la elaboración de sus textos formales. Requirió esfuerzo y paciencia, además de un acompañamiento constante de mi parte como docente para leer, revisar, comentar y devolver cada texto producido, lo cual implica una disposición cognitiva y afectiva para reconocer en los textos leídos al sujeto que los produce, corrige y reelabora.

El trabajo realizado durante el periodo escolar se cumplió de acuerdo con los cometidos de la experiencia educativa a través de la metodología afectiva que incluso fue a más, debido a que el cierre del curso incluyó que cada estudiante expusiera ante el grupo alguno de los textos producidos durante el semestre; actividad no considerada inicialmente en el programa de la asignatura. La experiencia de saberse autores y lectores competentes, cuando inicialmente no se consideraban capaces de lograrlo, fue un plus enriquecedor para ellos.

Para concluir, si bien lo que acontece en un grupo no puede generalizarse ni enunciarse en una ley, sí es posible apostar por prácticas pedagógicas que consideren estrategias dinámicas que no dejen afuera los intereses del estudiantado, para que, a partir de éstos, puedan ser atraídos a los objetivos de una asignatura o los fines de un taller o un seminario. Considerar que los cuerpos presentes en las aulas de las instituciones de educación superior importan, es dar cabida a un desempeño académico benéfico para estudiantes y docentes, amén de humanístico, necesario y urgente en nuestros tiempos confusos y desesperanzadores. De este modo, Lispector tiene razón: sentir es un hecho; y los afectos, la respuesta.

\section{Fuentes de consulta}

Ahmed, S. (2006). Doing Diversity Work in Higher Education in Australia. Educational Philosophy and Theory, 38(6), 745-768.

Boler, M. (1999). Feeling Power: Emotions and Education. New York: Routledge.

Claro, T. y Juan S. (2013). Calidad en educación y clima escolar: apuntes generales. Estudios Pedagógicos, 39(1), 347-359.

Ferry, L. (2009). La sabiduría de los mitos. Madrid: Taurus.

Hargreaves, A. (2001). Emotion and Geographies of Teaching. Teachers College Record, 103(6), 1056-1080.

Herrera, M. y Rico, B. (2014). El clima escolar como elemento fundamental de la convivencia en la escuela. Revista Escenarios, 12(7), 7-18.

Honneth, A. (1992). Integridad y desprecio. Motivos básicos de una concepción de la moral desde la teoría del reconocimiento. Isegoría 5, 78-92.

Howes, D. (2014). El creciente campo de los estudios sensoriales. RELACES, 15, 10-26.

Lispector, C. (2007). La hora de la estrella. Madrid: Siruela.

López, H. (2012). Feminismo y pedagogía: un enfoque espacial. En M. Belausteguigoitia y R. Lozano (Comps.). Pedagogías en espiral. Experiencias y prácticas. México: Universidad Nacional Autónoma de México-Programa Universitario de Estudios de Género, 51-67.

Najmanovich, D. (2016). El mito de la objetividad. La construcción colectiva de la experiencia. Buenos Aires: Editorial Biblos.

Sabido, R. O. (2017). Georg Simmel y los sentidos: una sociología relacional de la percepción. Revista Mexicana de Sociología, 79(2), 347-400.

Scott, J. (2001). Experiencia. La Ventana, 13. México: Universidad de Guadalajara, 42-73.

Youdell, D. y Armstrong, F. (2011). A politics beyond subjects: the affective choreographies and smooth spaces of schooling. Emotion, Space and Society, 4, 144-150.

Zembylas, M.; Bozalek, V.; y Shefer, T. (2014). Tronton's notion of privileged irresponsability and the reconceptualisation of care: implications for critical pedagogies of emotion in higher education. Gender and Education, 26(3), $200-214$. 